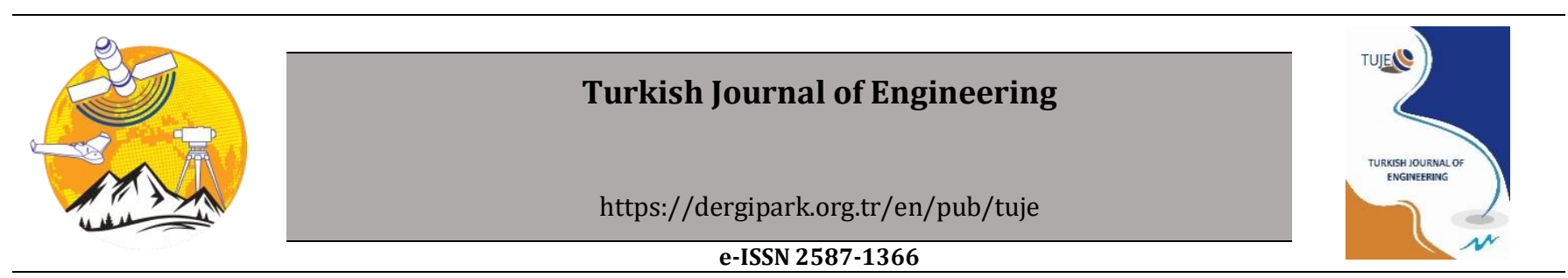

\title{
Production of new type insulation material: Expanded Perlite-Silica aerogel composite
}

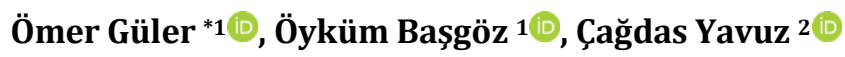 \\ ${ }^{1}$ Mersin University, Faculty of Engineering, Metallurgical and Material Engineering Department, Mersin, Turkey \\ ${ }^{2}$ Ege University, Solar Energy Institute, Izmir, Turkey
}

\author{
Keywords \\ Expanded Perlite \\ Silica aerogel \\ Insulation building material
}

\begin{abstract}
Silica aerogel is a class of nanoporous material with extremely high porosity (85-99.9\%) and specific surface area (500-1200 $\mathrm{m}^{2} / \mathrm{g}$ ), as in cause very low density, low thermal conductivity. But silica aerogel have some disadvantages. One of this disadvantages is high cost. In this study, to solve this problem has been used low cost precursor which is rice husk ash. Also, we try to improve porosity. To improve the porosity we used expanded perlite (EP). To produced $\mathrm{EP}$ is heated the perlite to $760-1100{ }^{\circ} \mathrm{C}$, at which point its native water is converted to vapor and the material is caused to expand to 4-20 times its original volume, then the high-porosity and lightweight aggregates are formed. In this study silica aerogels have been reinforced with EP to product new type composite material which is used as building insulation material. The prepared EP-silica aerogel composite was characterized using SEM and BET measurements.
\end{abstract}

\section{INTRODUCTION}

Kistler first introduced an idea about displacement of the liquid phase in the gel with gas in 1930s (Stolarski et al. 1999; Kistler 1931; Kistler 1932). For many years there are many potential applications for aerogel structures. These applications are listed as; heat insulation, sound insulation, oil spill cleanup, lowdielectric constant aerogel films in ultra-large integrated circuits, Cherenkov radiation detectors, electronic components, pharmaceutical distribution systems, chromatography, raw materials and synthesis for engineering rubber and ceramics adsorption (Aravind et al. 2010; Zulfiqar et al. 2015; Tang et al. 2017). These materials have a wide range of applications, they have very large surface area (500-100 $\mathrm{m}^{2} \mathrm{~g}^{-1}$ ), high porosity (\% 80-99.8) and low volumetric density (0.003-0.8 $\left.\mathrm{g} / \mathrm{cm}^{3}\right)$, low temperature Conductivity $\left(0.02 \mathrm{~W} \mathrm{~m}^{-1} \mathrm{~K}^{-1}\right)$, ultra-low dielectric constant (1.0-2.0) is due to their many impressive properties (Aravind et al. 2010; Wang et al. 2015). Although silica aerogel materials that studied for many years have such widespread using area and advanced properties, these advanced properties couldn' t utilized at the desired rate in the industrial area. This is because of the aerogel has low strength, low toughness and brittle (Zhou et al. 2018; Li et al. 2017).
The reason is that silica aerogel is fragile named as "pearl necklace". These pearl necklaces have 3-10 nm diameter silica nanoparticles, which are connected to each other by forming narrow inter-particle necks and forming a 3dimensional network (Ma et al. 2012).

Using common organic silica sources such as tetraethoxysilane (TEOS), polyethoxydisiloxane (PEDS) for industrial scale. This situation has been limited to using of silica aerogel. To maintain the industrial application of silica aerogel, it is a priority to find a costeffective and environmentally friendly synthesis route (Feng et al. 2018). Sodium silicate has been used as precursor to produce silica in industrial production. However, sodium silicate is formed by melting quartz sand and sodium carbonate at a very high temperature of $1300^{\circ} \mathrm{C}$ and this requires a large amount of energy. This method is hazardous for the environment. Because during the producing of 1 ton of silica, 0.53 tonnes of sulfuric acid and 0.53 tonnes of sodium carbonate were used and finally were produced 0.23 tonnes of carbon dioxide $\left(\mathrm{CO}_{2}\right), 0.74$ tonnes of sodium sulfate and 20 tonnes of waste water. In recent years, one of the most important problems in the world is the "greenhouse" effect, especially with regard to $\mathrm{CO}_{2}$. Therefore, finding a cheap source of preparing silica will allow the producing industrial scales of the silica aerogel. For industrial 
production, abundant biomass wastes such as rice husk, bamboo, wheat husk were gradually recognized as precursor silica (Liou et al. 2011).

To produced expanded perlite heating perlite to $760-1100^{\circ} \mathrm{C}$. At this temperature, the water in the perlite has been converted to steam and perlilte has a highly porous and light aggregate structure with 4-20 times increase compared to initial volume of the material (Wang et al. 2018). Moreover, perlite shows chemically inert and has important properties such as fire resistant, high sound insulation. Today, approximately $65 \%$ of the perlite producing is used by the construction industry. For insulating purpose, EP powder has been used as filler material in hollow bricks or as an additive in plasters (Pichór and Janiec 2009). Furthermore, the porous structure of expanded perlite creates a wide application area for composite materials. For example this composite materials, silica composite for lauric-palmitic-stearic acid/expanded perlite composite, vacuum insulation panel core, a novel paraffin/EP composite, capric acidpalmitic acid/EP composite, expanded perlite/paraffin composite, sodium nitrate/EP (Wang et al. 2018). $\mathrm{SiO}_{2}$ aerogel is an expensive material when used alone. But, combined by expanded perlite with silica aerogel to produce the composite material could be reduced amount of the $\mathrm{SiO}_{2}$ aerogel and cost of the producing.

In this work, the silica aerogel was synthesized by using rice husk as starting material and reinforced the perlite to this silica aerogel and heating to $1000{ }^{\circ} \mathrm{C}$ to produce expanded perlite (EP)/silica aerogel composite. This new type composite material, which can be used as building insulation material. The prepared EP-silica aerogel composite was characterized using SEM and BET.

\section{EXPERIMENTAL METHOD}

Rice Husk (RH) used for starting material. RH was supported from "Tat Bakliyat" company found in Mersin, Turkey. Chemicals that used in this work sodium hydroxide $(\mathrm{NaOH})$ (Isolab Co.), sulfuric acid $\left(\mathrm{H}_{2} \mathrm{SO}_{4}\right)$ (Merck Co.) and tetraethyl orthosilicate (TEOS) (Merck Co.). Perlite was supported from a company named as "Genperé".

In this work RH used as the starting material was first washed with distilled water and dried to remove contaminants. The $\mathrm{RH}$ was then heated to $600{ }^{\circ} \mathrm{C}$ for 5 hours under normal atmosphere in a muffle furnace (which would increase its $\mathrm{SiO}_{2}$ rate). The results of XRF analysis of calcined rice husk ash shows in Table 1. $\mathrm{SiO}_{2}$ value obtained as a result of calcination at $600{ }^{\circ} \mathrm{C}$ was $90,10 \%$. To carry out the extraction of silica from the synthesized rice husk ash, 5 gr rice husk ash (RHA) was extracted at $95^{\circ} \mathrm{C}$ in $1 \mathrm{M} \mathrm{NaOH}$ solution of $150 \mathrm{ml}$. The sodium silicate solution obtained after it was filtered to abolish contaminants that remained as undissolved waste. The filtered sodium silicate solution was neutralized using $1 \mathrm{~mol} /$ liter $\mathrm{H}_{2} \mathrm{SO}_{4}$. Silica hydrosol was obtained after this process. 1/10 volume of TEOS was added to the synthesized silica hydrosol to obtain gel. After addition of TEOS, amount of $10 \%$ Perlite was added. The gel obtained after this process kept at room temperature for 24 hours to carry out the aging step. It was then washed using de-ionized water to remove unwanted impurities from the aging gel structure. The washed gel was dried for 1 hour at $120{ }^{\circ} \mathrm{C}$ to obtain the final drying step and silica aerogel composite. After drying, it was heated to $1000{ }^{\circ} \mathrm{C}$ to obtained the expanded perlite in the composite and for increase the porosity in the structure. Fig. 1 shows the flow diagram compiling the production of perlite/ silica aerogel composite.

The prepared EP-silica aerogel composite was characterized using SEM and BET measurements.

Table 1. XRF results of rice husk ash

\begin{tabular}{ll}
\hline (\% mass) & $600{ }^{\circ} \mathrm{C}-5 \mathrm{sa}$ \\
\hline $\mathrm{Na}_{2} \mathrm{O}$ & 0,096 \\
\hline $\mathrm{MgO}$ & 0,76 \\
\hline $\mathrm{Al}_{2} \mathrm{O}_{3}$ & 0,35 \\
\hline $\mathrm{SiO}_{2}$ & 90,10 \\
\hline $\mathrm{P}_{2} \mathrm{O}_{5}$ & 0,97 \\
\hline $\mathrm{SO}_{3}$ & 0,53 \\
\hline $\mathrm{Cl}$ & 0,31 \\
\hline $\mathrm{K}_{2} \mathrm{O}$ & 5,15 \\
\hline $\mathrm{CaO}$ & 1,36 \\
\hline $\mathrm{MnO}$ & 0,15 \\
\hline $\mathrm{Fe} \mathrm{O}_{3}$ & 0,24 \\
\hline $\mathrm{ZnO}$ & 0,014 \\
\hline
\end{tabular}

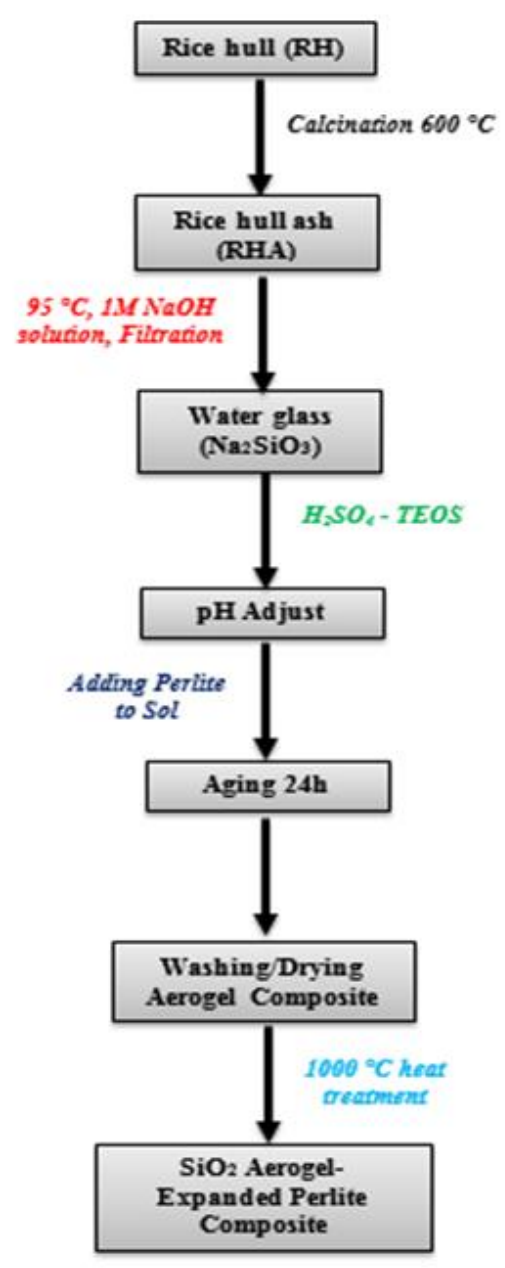

Figure 1. Flowchart for preparing $\mathrm{SiO}_{2}$ aerogel from rice husk ash -perlite composite 


\section{RESULTS}

Figure 2.a shows the SEM images of pure $\mathrm{SiO}_{2}$ aerogel and Figure 2.b, c shows the Perlite / $\mathrm{SiO}_{2}$ aerogel composite. The resulting SEM image is similar to a conventional airgel image. Because in aerogels, there is a chain-like arrangement of nano-sized particles. The resulting structure consists of many grains diffused into one another by the effect of high temperature. Aerogel structures combined with the effect of temperature to form larger structures. There are also many gaps between these particles. Dark colored parts indicated by arrows in the structure are unexpanded perlite added to aerogel. While this structure is expected to have a very high porosity, the amount of pores is negligible as can be seen from the Figure 2c. This can be explained by the fact that the unexpanded perlite contained in the aerogel does not expand even after heating to $1000{ }^{\circ} \mathrm{C}$. Although this temperature is suitable for explosion of perlite, there is no expansion of perlite at this temperature; can be explained by the lack of time. It also suggests that the non-explosion of unexpanded perlite surrounded by aerogels may be caused by inhibition of aerogels. In addition, in our previous study, after drying of silica aerogel at $120^{\circ} \mathrm{C}$, heat treatment under $1000^{\circ} \mathrm{C}$ resulted in nano stalactite structures (Başgöz and Güler 2020). The operating temperature of $1000{ }^{\circ} \mathrm{C}$ was particularly selected in this study. There are two reasons for this, one of these; conversion of perlite to expanded perlite; the second reason is to increase the porosity of the composite material to be obtained as a result of the formation of nano stalactite structures similar to the previous temperature. However, in this study, similar structures were not seen on SEM images in the process performed under $1000{ }^{\circ} \mathrm{C}$. This is due to the fact that perlite inside the structure does not allow the formation of nano stalactites. Because, in our study where nano stalactite structures were seen, the reason for the formation of these structures was that TEOS converted to $\mathrm{SiO}_{2}$ and Diethyl Ether at temperatures above $600{ }^{\circ} \mathrm{C}$ (Nurkowski et al. 2016), when this aerogel was placed in the oven the reaction occurred firstly and the resulting Diethyl Ether burned with the impact of the air and boosted the temperature of the particles in micron size caused by the formation of melting particles together with each other grew and formed a network-shaped structure. Gases from ignition of diethyl ether and air trapped in $\mathrm{SiO}_{2}$ particles by cause of rapid melting. If the time is enough, the volume of the gases trapped in the molten $\mathrm{SiO}_{2}$ increases up to $800 \%$ because of the heat. Due to this expansion, the particles began to swell like a balloon. Under the effect of temperature, these particles also convert to Cristobalite structure. But, due to the high strength of the silicas, the internal air pressure cannot ecplode the swollen silicas. They appear with cracks on the surface. In this work, perlite prevented this formation.

The $\mathrm{N}_{2}$ adsorption / desorption isotherms of the silica aerogel-perlite composite are given in Figure 3. The isotherm obtained according to IUPAC classification complies with type IV. Silica airgel appears to be mesoporous (ALOthman et al. 2012). The BET value of silica airgel-pearlite composite was found $30,6762 \mathrm{~m}^{2} / \mathrm{g}$.
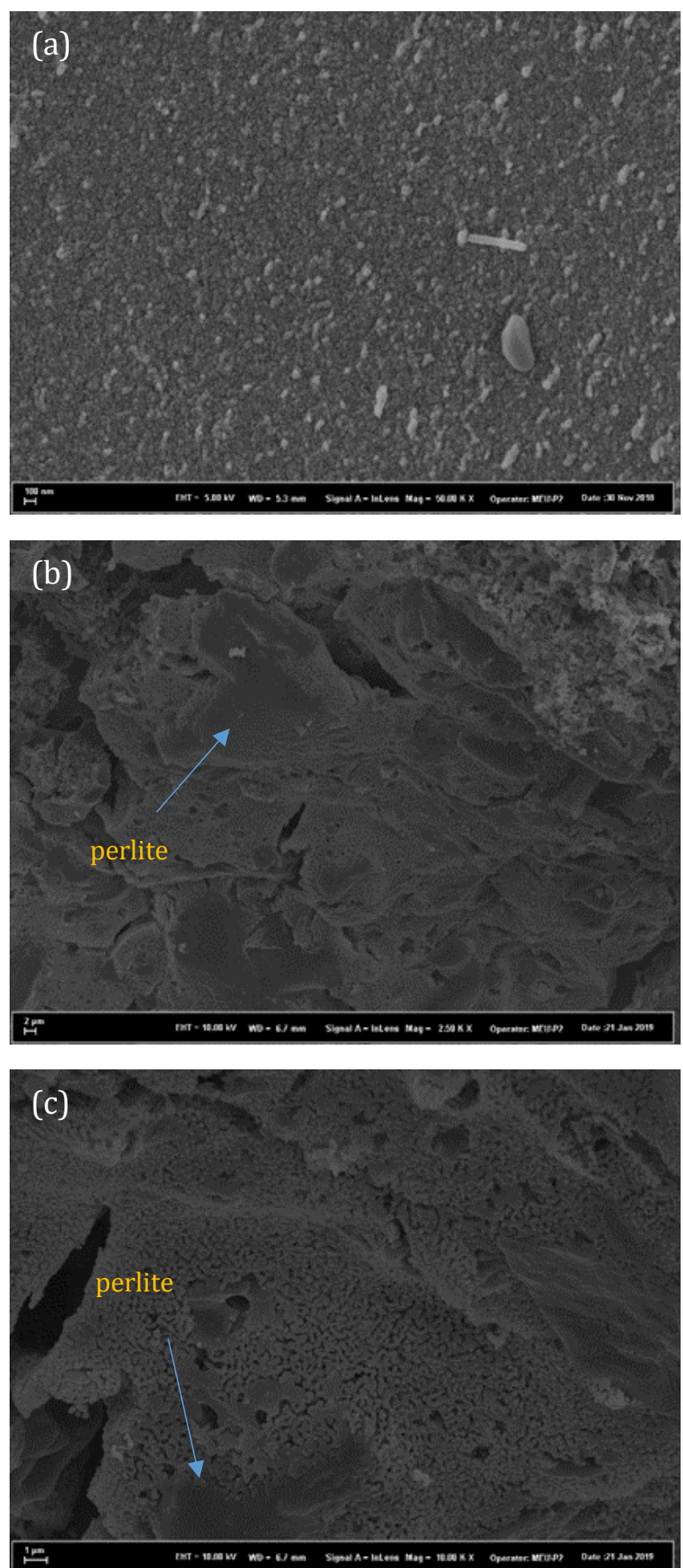

Figure 2. SEM images of pure $\mathrm{SiO}_{2}$ aerogel (a), perlite / $\mathrm{SiO}_{2}$ aerogel composite $(b, c)$.

Table 2. Pore structure values of Pure $\mathrm{SiO}_{2}$ Aerogel and Perlite $/ \mathrm{SiO}_{2}$ aerogel composite

\begin{tabular}{lll}
\hline & $\begin{array}{l}\text { Pure } \mathrm{SiO}_{2} \\
\text { Aerogel }\end{array}$ & $\begin{array}{l}\text { Perlite/SiO } \\
\text { Aerogel Composite }\end{array}$ \\
\hline $\begin{array}{l}\text { Adsorption Average } \\
\text { Pore Diameter }\left(\mathrm{A}^{\circ}\right)\end{array}$ & 90,5627 & 62,1846 \\
\hline $\begin{array}{l}\text { Pore Volume } \\
\left(\mathrm{cm}^{3} / \mathrm{g}\right)\end{array}$ & 0,546639 & 0,047690 \\
\hline $\begin{array}{l}\mathrm{BET} \text { Surface Area } \\
\left(\mathrm{m}^{2} / \mathrm{g}\right)\end{array}$ & 241,4410 & 30,6762 \\
\hline
\end{tabular}




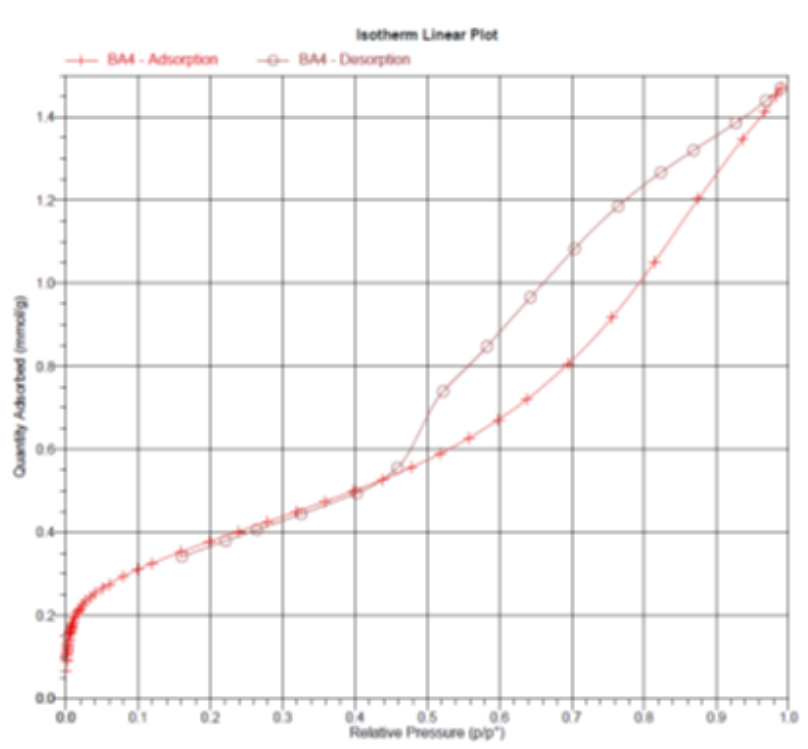

Figure 3. $\mathrm{N}_{2}$ adsorption / desorption isotherm of Perlite$\mathrm{SiO}_{2}$ composite

Pore structure parameters for pure $\mathrm{SiO}_{2}$ aerogel and Perlite / $\mathrm{SiO}_{2}$ aerogel composite are given in Table 2 . Adsorption average pore diameter $90.5627 \mathrm{~A}^{\circ}$, Maximum pore volume $0.546639 \mathrm{~cm}^{3} / \mathrm{g}$ and BET Surface Area value was determined as $241.441 \mathrm{~m}^{2} / \mathrm{g}$ for pure $\mathrm{SiO}_{2}$ aerogel. For Perlite / $\mathrm{SiO}_{2}$ aerogel composite, these values were found as $62,1846 \mathrm{~A}^{\circ}, 0.047690 \mathrm{~cm}^{3} / \mathrm{g}$ and $30.6762 \mathrm{~m}^{2} / \mathrm{g}$, respectively. BET Surface Area value decreased as a result of perlite addition. This is considered to be due to the addition of perlite, and the main reason is believed to be the elevation of the sample to $1000{ }^{\circ} \mathrm{C}$ for the expansion of perlite in the perlite-silica aerogel composite. Due to the air trapped between the particles of aerogels with this temperature, the gap decreased with the growth and association of aerogels and caused the BET area to decrease. Pre-widening the perlite and reinforcing it to Silica aerogel will improve the properties of the composite.

In this study, particle size of perlite scattered in the composite and surrounded by aerogel nanoparticle is approximately $5 \mu \mathrm{m}$. SEM images suggest that perlite additive increases the particle size of the composite and decreases accordingly in the BET surface area. This is consistent with the relationship between specific surface area and particle size reported in the literature (Gregg et al. 1967; Yang et al. 2020).

\section{CONCLUSIONS}

Reinforcing expanded perlite to silica aerogels can both reduce the cost of silica aerogels and increase the application areas. For this purpose, silica aerogels were produced from paddy husk and it was aimed to expand the perlite by increasing the composite to $1000{ }^{\circ} \mathrm{C}$ by adding unexpanded perlite structure. However, exposure of silica aerogels at this temperature has been shown to reduce the BET surface area expected to increase and has lost its properties. In addition, silica aerogels made it difficult to expand perlite at this temperature. Apart from this method, it has been concluded that better results can be obtained by producing composite using different methods

\section{ACKNOWLEDMENT}

The authors would like to acknowledge the financial support of Mersin University Department of Scientific Research Projects (Project No: 2019-3-TP3-3764).

\section{REFERENCES}

ALOthman Z A (2012). A review: Fundamental aspects of silicate mesoporous materials. Materials, 5(12), 2874-2902. DOI: 10.3390/ma5122874

Aravind P R, Shajesh P, Soraru G D \& Warrier K G K (2010). Ambient pressure drying: A successful approach for the preparation of silica and silica based mixed oxide aerogels. Journal of Sol-Gel Science and Technology, 54(1), 105-117. DOI: 10.1007/s10971-010-2164-2

Başgöz Ö \& Güler Ö (2020). The unusually formation of porous silica nano-stalactite structure by high temperature heat treatment of $\mathrm{SiO}_{2}$ aerogel synthesized from rice hull. Ceramics International, 46(1), 370-380. DOI: 10.1016/j.ceramint.2019.08.271

Feng Q, Chen K, Ma D, Lin H, Liu Z, Qin S \& Luo Y (2018). Synthesis of high specific surface area silica aerogel from rice husk ash via ambient pressure drying. Colloids and Surfaces A: Physicochemical and Engineering Aspects, 539, 399-406. DOI: 10.1016/j.colsurfa.2017.12.025

Gregg S J, Sing K S W \& Salzberg H W (1967). Adsorption surface area and porosity. Journal of the Electrochemical Society, 114(11), 279C.

Kistler S S (1931). Coherent expanded aerogels and jellies. Nature, 127, 741(3211). DOI: 10.1038/127741a0

Kistler S S (1932). Coherent expanded-aerogels. Rubber Chemistry and Technology, 5(4), 600-603. DOI: 10.5254/1.3539386

Li C, Cheng X, Li Z, Pan Y, Huang Y \& Gong L (2017). Mechanical, thermal and flammability properties of glass fiber film/silica aerogel composites. Journal of Non-Crystalline Solids, 457, 52-59. DOI: 10.1016/j.jnoncrysol.2016.11.017

Liou T H \& Yang C C (2011). Synthesis and surface characteristics of nanosilica produced from alkaliextracted rice husk ash. Materials science and engineering: $\quad B, \quad 176(7), \quad 521-529$. DOI: 10.1016/j.mseb.2011.01.007

Ma X, Zhou B, Gao W, Qu Y, Wang L, Wang Z, \& Zhu Y (2012). A recyclable method for production of pure silica from rice hull ash. Powder Technology, 217, 497-501. DOI: 10.1016/j.powtec.2011.11.009

Nurkowski D, Buerger P, Akroyd J, Mosbach S \& Kraft M (2016). Skeletal chemical mechanism of hightemperature TEOS oxidation in hydrogen-oxygen environment. Combustion and Flame, 166, 243-254. DOI: $10.1016 /$ j.combustflame.2016.01.025

Pichór W \& Janiec A (2009). Thermal stability of expanded perlite modified by mullite. Ceramics International, 35(1), 527-530. DOI: 10.1016/j.ceramint.2007.10.008

Stolarski M, Walendziewski J, Steininger M \& Pniak B (1999). Synthesis and characteristic of silica 
aerogels. Applied Catalysis A: General, 177(2), 139148. DOI: $10.1016 / S 0926-860 X(98) 00296-8$

Tang X, Sun A, Chu C, Yu M, Ma S, Cheng Y, Guo J \& Xu G (2017). A novel silica nanowire-silica composite aerogels dried at ambient pressure. Materials \& Design, 115, 415-421. DOI: 10.1016/j.matdes.2016.11.080

Wang J, Zhang Y, Wei Y \& Zhang X (2015). Fast and onepot synthesis of silica aerogels via a quasi-solventexchange-free ambient pressure drying process. Microporous and Mesoporous Materials, 218, 192198. DOI: $10.1016 /$ j.micromeso.2015.07.019

Wang L, Li Z, Jing Q \& Liu P (2018). Synthesis of composite insulation materials-expanded perlite filled with silica aerogel. Journal of Porous Materials, 25(2), 373-382. DOI: 10.1007/s10934017-0448-4
Yang H, Li C, Yue X, Huo J, Ye F, Liu J, Shi F \& Ma J (2020). New BN/SiOC aerogel composites fabricated by the sol-gel method with excellent thermal insulation performance at high temperature. Materials \& Design, 185, $108217 . \quad$ DOI: 10.1016/j.matdes.2019.108217

Zhou T, Cheng X, Pan Y, Li C, Gong L \& Zhang H (2018). Mechanical performance and thermal stability of glass fiber reinforced silica aerogel composites based on co-precursor method by freeze drying. Applied Surface Science, 437, 321-328. DOI: 10.1016/j.apsusc.2017.12.146

Zulfiqar U, Subhani T \& Husain S W (2015). Towards tunable size of silica particles from rice husk. Journal of Non-Crystalline Solids, 429, 61-69. DOI: 10.1016/j.jnoncrysol.2015.08.037

(C) Author(s) 2021.

This work is distributed under https://creativecommons.org/licenses/by-sa/4.0/ 